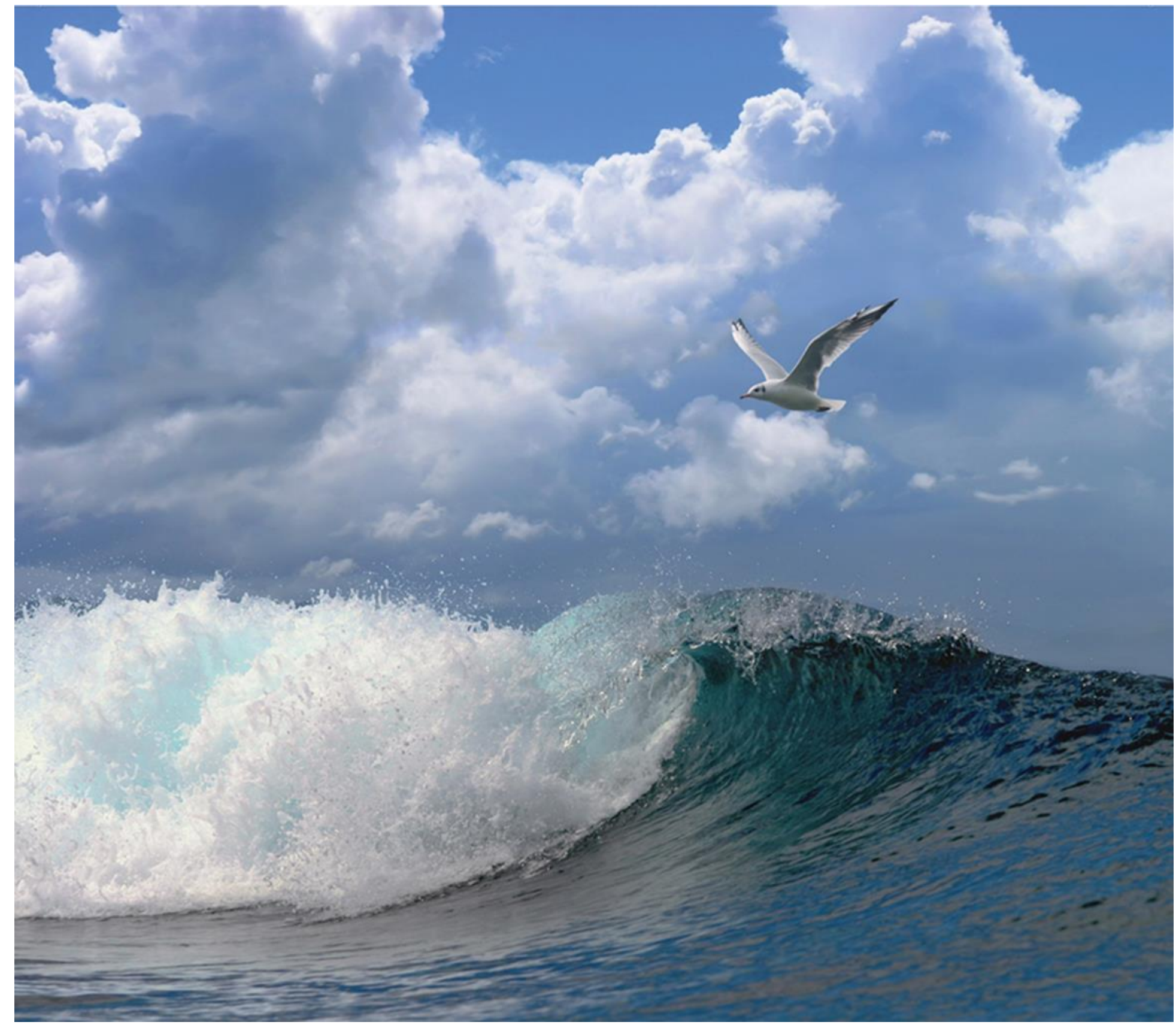

\title{
Quickscan mogelijke effecten gaswinning bij Borkumse Stenen op platteoesterrif
}




\section{Quickscan mogelijke effecten gaswinning bij Borkumse Stenen op platteoesterrif}


Keywords: Borkumse Stenen, platte oester, gaswinning.

Opdrachtgever: WWF

T.a.v.: Mevr. E. Reuchlin-Hugenholtz

Driebergseweg 10

3708 JB Zeist

Dit rapport is gratis te downloaden van https://doi.org/10.18174/519603

Wageningen Marine Research verstrekt geen gedrukte exemplaren van rapporten.

Wageningen Marine Research is ISO 9001:2015 gecertificeerd.

\section{(C) Wageningen Marine Research}

Wageningen Marine Research, instituut binnen de rechtspersoon Stichting Wageningen Research, hierbij vertegenwoordigd door Dr. M.C.Th. Scholten, Algemeen directeur

KvK nr. 09098104,

WMR BTW nr. NL 8113.83.696.B16.

Code BIC/SWIFT address: RABONL2U

IBAN code: NL 73 RABO 0373599285
Wageningen Marine Research aanvaardt geen aansprakelijkheid voor gevolgschade, noch voor schade welke voortvloeit uit toepassingen van de resultaten van werkzaamheden of andere gegevens verkregen van Wageningen Marine Research. Opdrachtgever vrijwaart Wageningen Marine Research van aanspraken van derden in verband met deze toepassing.

Alle rechten voorbehouden. Niets uit deze uitgave mag weergegeven en/of gepubliceerd worden, gefotokopieerd of op enige andere manier gebruikt worden zonder schriftelijke toestemming van de uitgever of auteur. 


\section{Inhoud}

Samenvatting $\quad 4$

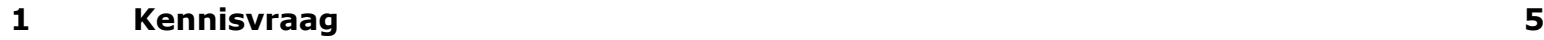

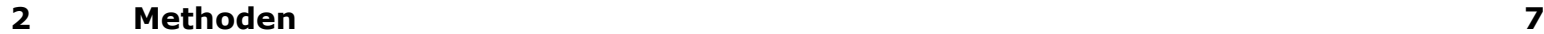

$\begin{array}{llr}3 & \text { Resultaten } & 8\end{array}$

3.1 Huidige staat van de Borkumse Stenen en het aangelegde oesterrif 8

3.2 Potentiële effecten van offshore activiteiten op natuurwaarden 9

$\begin{array}{ll}3.2 .1 & \text { Oppervlakteverlies } \\ 3.2 .2 & 10\end{array}$

$\begin{array}{ll}3.2 .2 \text { Verontreiniging } & 10\end{array}$

$\begin{array}{ll}3.2 .3 \text { Verstoring substraat (zeebodem) } & 10\end{array}$

3.2.4 Vertroebeling 11

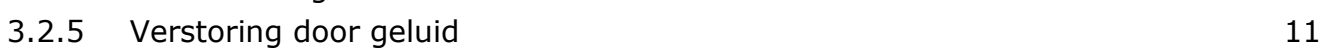

3.2.6 Verstoring door licht en optische verstoring $\quad 12$

$\begin{array}{lll}3.3 & \text { Overige risico's } & 13\end{array}$

3.4 Potentiële effecten op benthos en platte oesters in het bijzonder 13

$\begin{array}{ll}3.5 & \text { Cumulatieve impacts } \\ \end{array}$

$4 \quad$ Kwaliteitsborging $r$

$\begin{array}{lr}\text { Literatuur } & 16\end{array}$ 


\section{Samenvatting}

In 2018 is een platteoesterrif bij de Borkumse Stenen aangelegd als natuurherstelmaatregel door het Wereld Natuur Fonds. In het gebied zijn ook gasvelden aangetroffen waarnaar proefboringen worden uitgevoerd. In dit rapport is een quickscan uitgevoerd van mogelijke effecten van alle bij gaswinning horende activiteiten op het benthos van de Borkumse Stenen en het aangelegde oesterrif. 


\section{$1 \quad$ Kennisvraag}

Het Wereld Natuur Fonds Nederland (WWF NL) heeft in 2018 een platteoesterrif (hierna oesterrif genoemd) bij de Borkumse Stenen aangelegd (Figuur 1), als natuurherstelmaatregel. Het bedrijf Oranje Nassau Energie heeft in het GEMS-project (Gateway to the Ems) in het gebied N05-A in 2017 laagcalorische gasvelden aangetroffen. $\mathrm{Er}$ is al 3D-seismisch verkennend onderzoek uitgevoerd dat in 2019 zal worden voortgezet. Ook zijn proefboringen uitgevoerd in 2017 en 2018. Verdere proefboringen zijn gepland. Vervolgens kan gedurende een periode van 10-25 jaar gaswinning plaats gaan vinden, waarvoor in 2021-2022 een productieplatform zal worden geplaatst. Begin 2019 wordt de locatie en de route naar land geselecteerd op basis van minimalisatie van milieueffecten.

Het WWF maakt zich met name zorgen over de effecten die gaswinning op het oesterrif kunnen hebben en in bredere zin over de effecten op andere natuurwaarden van het gebied. WWF heeft daarom Wageningen Marine Research (WMR) verzocht een quickscan te maken om mogelijke effecten van gaswinning onder de aandacht te kunnen brengen.

De vragen die bij het WWF leven zijn:

- In welke staat bevinden de Borkumse Stenen en het aangelegde oesterrif zich voordat resp. het verkennend $3 \mathrm{~d}$-seismisch onderzoek, proefboringen en de uiteindelijke gaswinning worden verricht? (m.a.w. beschrijf de kwaliteit van de nul-situatie)

- Welke eventuele schadelijke effecten hebben alle bij gaswinning horende activiteiten op natuurwaarden van het habitat bij en om de oesterbank en van de Borkumse Stenen (incl. op zeezoogdieren zoals bruinvis, zeehonden, vissen zoals haaien, roggen, kabeljauw, vogels, benthos, etc.) in brede zin ?

- Wat zijn specifieke schadelijke effecten van de alle bij gaswinning horende activiteitengasactiviteiten op het benthos van de Borkumse Stenen en het aangelegde oesterrif in het bijzonder?

- Op welke afstand spelen effecten op benthos/oesterriffen een rol? Zou er bijvoorbeeld een bepaalde afstand in acht kunnen worden genomen door het gasbedrijf vanaf waar het veilig kan opereren en het oesterrif geen schade oploopt?

- Kort commentaar op de rol van cumulatieve impacts (van een combinatie van verschillende activiteiten) in het gebied. 


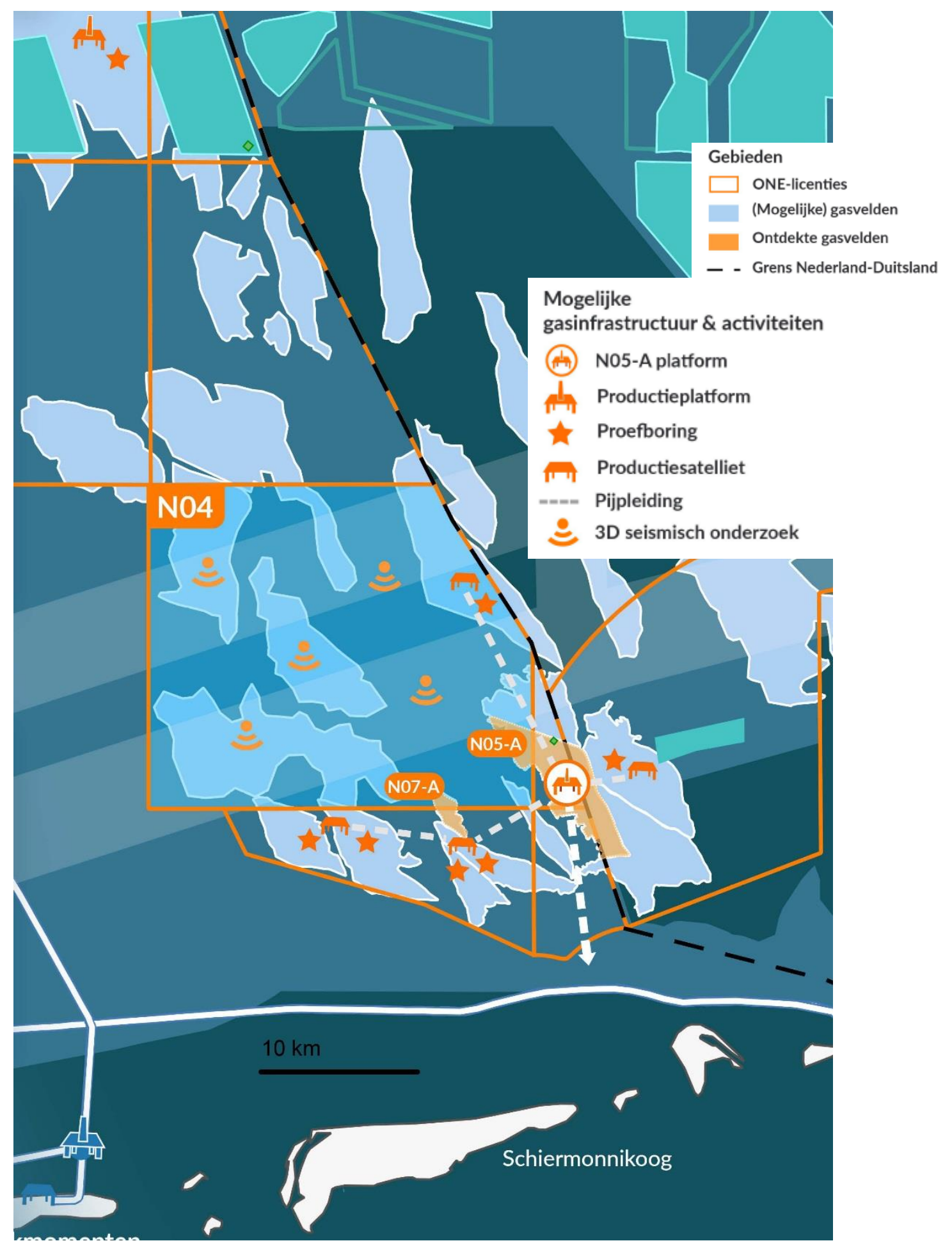

Figuur 1: Uitsnede uit de infographic aangeleverd door het WWF (bron: Oranje-Nassau), met de locatie van het WWF-oesterrif (groen vierkantje nabij platform, aangegeven door WWF) t.o.v. de mogelijke gasinfrastructuur en activiteiten. Het oesterrif ligt aan de noordkant binnen de contouren van het ontdekte gasveld NO5-A. 


\section{Methoden}

Voor deze zeer beknopte deskstudie is gebruik gemaakt van bestaande kennis binnen WMR over drukfactoren van olie- en gasactiviteiten, aangevuld met een literatuurstudie naar mogelijke effecten op benthos (met speciale aandacht voor de in 2018 aangelegde platte oesterbank bij de Borkumse Stenen). Hiervoor is gebruik gemaakt van de digitale bibliotheek van de Wageningen Universiteit met de zoekmachine SCOPUS. Gezien de aard van deze studie, een quickscan, zijn de (potentiële) natuurwaarden van het gebied en mogelijke effecten daarop niet uitvoerig beschreven. Een verdere beperking is het ontbreken van informatie over de voorgenomen activiteiten. De potentiële effecten, die in dit briefrapport worden beschreven, kunnen daarom niet worden beschouwd als een nauwkeurige inschatting van de gevolgen van het ontwikkelen van het gasveld NO5-A voor de natuurwaarden in het gebied. Het geeft slechts een indicatie van mogelijke gevolgen. Voor een betere, nauwkeurige inschatting, waarbij ook het uitsluiten van (significante) effecten mogelijk is, is een uitgebreide studie noodzakelijk. 


\section{Resultaten}

\subsection{Huidige staat van de Borkumse Stenen en het aangelegde oesterrif}

Het gebied 'Borkumse Stenen' ligt in de Noordzee ten noorden van Schiermonnikoog en grenst aan de zuidzijde aan het Nederlandse Natura 2000-gebied Noordzeekustzone en aan de oostzijde aan het Duitse Natura 2000-gebied 'Borkum Riffgrund' (Figuur 2: Potentiële riffen in het onderzoeksgebied Borkumse Stenen (Bos et al., 2014), met een ingezette figuur van de ligging van het gebied Borkumse Stenen in het Nederlandse deel van de Noordzee (Vrooman et al., 2018). Figuur ). Het gebied is ca. 10 tot $40 \mathrm{~m}$ diep, met maximale stroomsnelheden tussen 0,4 en 1,0 m/s en watertemperaturen variërend tussen 3 en $19^{\circ} \mathrm{C}$ (Joschko et al., 2008, Coolen et al., 2015). In het gebied worden grofweg drie verschillende substraattypes onderscheiden (Bos et al., 2014): 1) matig fijn tot matig grof zand; 2) dichte velden van de kokerworm Lanice conchilega op zand ( $>500$ ind/m2); en 3) grind/keien/stenen (habitattype H1170 'riffen'). Dit harde substraat is zeer dicht begroeid. Binnen het onderzochte deel van de Borkumse Stenen is in het gebied met het harde substraat de hoogste biodiversiteit (hoge dichtheden, grote soortenrijkdom) gevonden. In totaal zijn er 199 taxa in het studiegebied gedetermineerd (Bos et al., 2014). Binnen het gehele gebied Borkumse Stenen bestaat mogelijk 1980 ha uit H1170 (Bos et al., 2014).

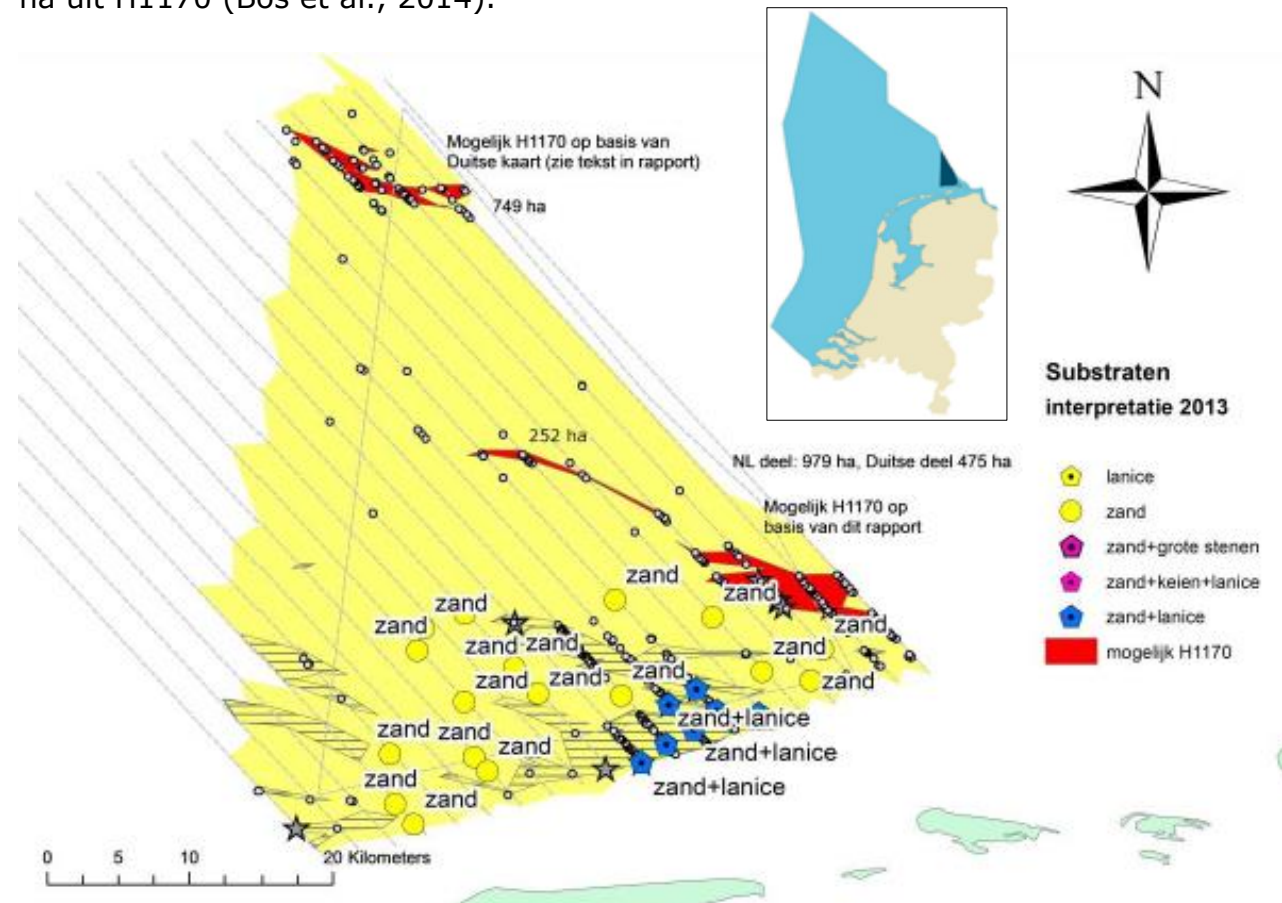

Figuur 2: Potentiële riffen in het onderzoeksgebied Borkumse Stenen (Bos et al., 2014), met een ingezette figuur van de ligging van het gebied Borkumse Stenen in het Nederlandse deel van de Noordzee (Vrooman et al., 2018).

In mei 2018 is een natuurherstelproject in het gebied de Borkumse Stenen gestart, waarbij op zo'n 20 meter diepte ca. $5500 \mathrm{~kg}$ platte oesters (naar schatting 80.000 individuele oesters) zijn geplaatst, afkomstig uit Noorwegen, onder meer op 3-D geprinte rifstructuren (Didderen et al., in prep). Vervolgens is in juli 2018 een veldbezoek gebracht en zijn een aantal oesters meegenomen naar het laboratorium voor verder onderzoek. De resultaten van dit pilotproject zijn veelbelovend: de volwassen oesters overleven in het gebied, laten groei, reproductie en een goede conditie zien en er zijn ook oesterlarven waargenomen direct afkomstig van de door WNF geplaatste volwassen oesters (Didderen et al., in prep). Of oesterlarven zich uiteindelijk succesvol zullen vestigen in het gebied moet nog blijken. Dat is in januari 2019 nog niet bekend. De volgende monitoring staat gepland voor het voorjaar/zomer 2019. 


\subsection{Potentiële effecten van offshore activiteiten op natuurwaarden}

Drukfactoren die gerelateerd zijn aan de bij gaswinning horende activiteiten (Tabel 1) kunnen potentiële effecten veroorzaken op natuurwaarden van het gebied. Deze worden per drukfactor onderaan de tabel toegelicht. Eventueel genoemde schattingen van de omvang van drukfactoren zijn gebaseerd op willekeurige / generieke activiteiten en zijn niet specifiek voor de potentiële activiteiten met betrekking tot gasveld NO5-A.

Tabel 1 Matrix activiteiten - drukfactoren (op basis van Tamis et al., 2011). X: voorkomen/optreden van de drukfactor door de activiteit.

\begin{tabular}{|c|c|c|c|c|c|c|}
\hline Activiteit & 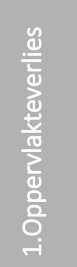 & 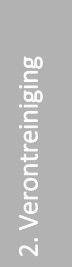 & 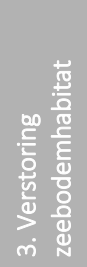 & 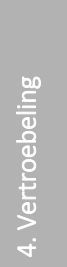 & 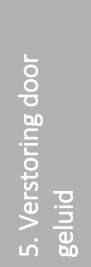 & 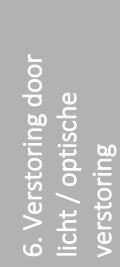 \\
\hline \multicolumn{7}{|l|}{ Exploratiefase } \\
\hline seismisch onderzoek & & $x$ & & & $x$ & $x$ \\
\hline \multicolumn{7}{|l|}{ Boorfase } \\
\hline plaatsen en gebruik boorplatform & $x$ & $\#^{1}$ & $x$ & $x$ & $x$ & $\mathrm{x}$ \\
\hline boren exploratie- en productieputten & & $\#^{1}$ & $x$ & & $x$ & \\
\hline heien & & & $\#^{2}$ & & $x$ & \\
\hline lozing van boorspoeling en boorgruis & & $x$ & $x$ & $x$ & & \\
\hline lozing van regen-, spoel- en schrobwater & & $x$ & & & & \\
\hline lozing van sanitair afvalwater & & $x$ & & & & \\
\hline productietesten / affakkelen & & & & & $\mathrm{x}$ & $x$ \\
\hline gebruik stand-by boot & & $\mathrm{X}$ & & & $x$ & $x$ \\
\hline \multicolumn{7}{|l|}{ Installatiefase } \\
\hline leggen en gebruik pijpleidingen & $\mathrm{x}$ & $x$ & $x$ & $x$ & $x$ & $x$ \\
\hline plaatsen platform & $\#^{3}$ & $x$ & $x$ & $x$ & $x$ & $x$ \\
\hline \multicolumn{7}{|l|}{ Productiefase * } \\
\hline normale bedrijfsvoering hoofdplatform & $x$ & $\#^{4}$ & & & $x$ & $x$ \\
\hline normale bedrijfsvoering satelliet & $x$ & & & & & $x$ \\
\hline lozing productiewater & & $x$ & & & & \\
\hline lozing van regen-, spoel- en schrobwater & & $x$ & & & & \\
\hline aangroeiwering en corrosiepreventie & & $x$ & & & & \\
\hline lozing van sanitair afvalwater & & $x$ & & & & \\
\hline onderhoud platform & & $\mathrm{x}$ & & & $x$ & \\
\hline \multicolumn{7}{|l|}{ Transport } \\
\hline helikopters & & & & & $x$ & $x$ \\
\hline schepen & & $x$ & & & $x$ & $x$ \\
\hline \multicolumn{7}{|l|}{ Ontmanteling } \\
\hline verwijderen pijpleidingen & & $x$ & $x$ & $x$ & $x$ & $x$ \\
\hline verwijderen platform & & $x$ & $x$ & $x$ & $x$ & $x$ \\
\hline \multicolumn{7}{|c|}{ Tijdens de productiefase vinden emissies naar de lucht door verbrandingsgassen plaats, bijvoorbeeld afkomstig van generatoren voor de } \\
\hline \multicolumn{7}{|c|}{ elektriciteitsopwekking, gasmotoren of compressoren. Ook vinden emissies naar de lucht van onverbrande koolwaterstoffen plaats door het } \\
\hline \multirow{2}{*}{\multicolumn{7}{|c|}{$\begin{array}{l}\text { van druk aflaten van de installaties, het afblazen van gassen en lekverliezen. Daarnaast ontstaan reststoffen die worden afgevoerd naar het } \\
\text { vasteland. Deze emissies zijn hier buiten beschouwing gelaten vanwege de focus op het lokale mariene milieu. }\end{array}$}} \\
\hline & & & & & & \\
\hline \multicolumn{7}{|c|}{ \# Deze drukfactor speelt wel een rol maar wordt (ook) meegenomen in afzonderlijke activiteiten en is hier niet genoemd om dubbel tellen te } \\
\hline \multicolumn{7}{|c|}{ voorkomen: 1) verontreiniging tijdens de boorfase wordt veroorzaakt door diverse lozingen en scheepvaart; 2 ) verstoring van de zeebodem } \\
\hline \multicolumn{7}{|c|}{ door heien wordt meegenomen bij het boren van de putten (is onderdeel van het boorproces); 3) oppervlakteverlies door een } \\
\hline \multicolumn{7}{|c|}{ productieplatform wordt meegenomen bij de productiefase; 4) verontreiniging tijdens de productiefase wordt veroorzaakt door diverse } \\
\hline lozingen, aangroeiwering en corrosiepreventie & & & & & & \\
\hline
\end{tabular}




\subsubsection{Oppervlakteverlies}

Door het plaatsen van faciliteiten op de zeebodem is een deel van het oppervlak niet meer beschikbaar voor het oorspronkelijke biologisch gebruik en zal (een deel van) de aldaar aanwezige biota worden vernietigd. Voor het fysiek verlies door een platform voor (olie- en) gaswinning wordt een cirkelvormig oppervlak met een straal van 100 meter gehanteerd (Ministerie van I\&W en Ministerie van LNV, 2018). Pijpleidingen worden over het algemeen ingegraven en veroorzaken verstoring (zie punt 3) maar geen verlies van oppervlak. Alleen bij kruisingen van leidingen wordt steenstort toegepast waarbij naar schatting een oppervlak van $500 \mathrm{~m}^{2}$ verloren gaat (Ministerie van I\&W en Ministerie van LNV, 2018). Het platform en kruisende leidingen zouden daarom in ieder geval op ruime afstand (>100 $\mathrm{m}$ ) van het oesterrif geplaatst moeten worden om effecten te vermijden. Om effecten van oppervlakteverlies op de natuurwaarden van het gebied te minimaliseren zouden de meest kwetsbare gebieden (velden van de kokerworm Lanice conchilega en de locaties met grind/keien/stenen) vermeden moeten worden.

\subsubsection{Verontreiniging}

Verontreiniging door regen-, spoel-, en schrobwater (RSS-water) betreft koolwaterstoffen, die via een gesloten drainagesysteem gereguleerd worden geloosd. Sanitair afvalwater kan verontreinigd zijn met organische stoffen en reinigingsmiddelen. Door de aanwezigheid van een behandelingsinstallatie voor sanitair afvalwater zullen effecten echter gering zijn. Productiewater bestaat uit het formatiewater en gecondenseerd water dat met het gas is meegeproduceerd. Dit water kan verontreinigd zijn met koolwaterstoffen, zware metalen en productiechemicaliën. Ook kan het radioactieve componenten bevatten (afhankelijk van de geologische formatie). Nadat het productiewater behandeld is en voldoet aan wettelijke lozingseisen kan het offshore geloosd worden. In sommige gevallen wordt het productiewater niet geloosd maar in hetzelfde of in een vergelijkbare reservoir geïnjecteerd (herinjectie). Verder kan verontreiniging door scheepvaart verwacht worden bij alle activiteiten waarbij schepen worden ingezet. Lokale effecten daarvan zijn te verwaarlozen. De gevolgen voor het milieu door het gebruik van aluminium-zink anoden is beperkt tot lokale effecten op het platformoppervlak en dragen op die manier bij aan de aangroeiwering (Tamis et al., 2011). Een algemene schatting van de afstand tot het platform waarbij geen effecten van verontreiniging meer worden verwacht is $500 \mathrm{~m}$ (Tamis et al., 2011). Indien het platform op ruime afstand (> $500 \mathrm{~m}$ ) van het oesterrif wordt geplaatst, lijken er met betrekking tot verontreiniging verwaarloosbare of geen effecten te zullen optreden.

\subsubsection{Verstoring substraat (zeebodem)}

Het plaatsen en verwijderen van het platform, het plaatsen van de pijpleidingen, het boren van putten en de lozing van boorspoeling en boorgruis hebben een direct effect op het habitat. Bij het plaatsen van een platform ontstaat er schade aan de bestaande bodemfauna en er wordt nieuw (hard) substraat geïntroduceerd, waarop zich andere soorten kunnen vestigen (Coolen, 2017). Binnen een zone van $500 \mathrm{~m}$ rondom de platforms zijn overige activiteiten uit veiligheidsoverwegingen uitgesloten. Mocht het zo zijn dat hierdoor visserij wegvalt, kan een refugium ontstaan (Duineveld et al., 2007).

Het plaatsen van pijpleidingen veroorzaakt een verstoring van het sediment van naar schatting ca. 10 $\mathrm{m}$ aan weerszijden van de leiding (Tamis et al., 2011). Ook hier geldt dat leidingen ruim uit de buurt van het oesterrif zouden moeten worden geplaatst.

Het boren van putten verstoort het substraat door het plaatsen van de buizen, door het boren en door eventueel vrijkomend cement en spacers. Boven in de put is de diameter ongeveer $90 \mathrm{~cm}$. Een overschot aan cement dat op de zeebodem terecht komt, zou een klein oppervlak (één tot enkele vierkante meters) van de zeebodem kunnen bedekken en de aanwezige biota verstikken. Het hierdoor beïnvloede oppervlak zal zich nabij het lozingspunt bevinden. 
Door lozing van boorspoeling en -gruis wordt het natuurlijk substraat lokaal bedekt met het geloosde materiaal. In de praktijk blijkt dat $90 \%$ van het geloosde boorgruis binnen 100 meter van het platform bezinkt (NOGEPA, 2001). Naar schatting wordt een gebied van ca. 0,8 ha bedekt met een laagdikte van meer dan $1 \mathrm{~mm}$, waarbij dichtbij het lozingspunt een laagdikte van 1 tot $3 \mathrm{~cm}$ kan ontstaan (Tamis et al., 2011). N.B. Deze schattingen zijn gebaseerd op een willekeurige boring en zijn niet specifiek voor de potentiële activiteiten met betrekking tot gasveld NO5-A. Indien de activiteiten op ruime afstand (> $500 \mathrm{~m}$ ) van het oesterrif plaatsvinden lijken er met betrekking tot fysieke verstoring verwaarloosbare of geen effecten te zullen optreden.

\subsubsection{Vertroebeling}

Vertroebeling betreft een toename van gesuspendeerd materiaal in de waterkolom. Een verhoogde troebelheid in de waterkolom kan effect hebben op de primaire productie (vermindering algengroei) of hindering van zichtjagers veroorzaken. Daarnaast kunnen deeltjes in het water ook leiden tot een fysiek effect door het verstoppen van ademhalingsorganen (zoals kieuwen), of het verstoren van het verzamelen van voedsel. Dit laatste is voornamelijk het geval als de grootte van de (anorganische) deeltjes vergelijkbaar is met die van voedseldeeltjes. De hoogste concentraties van gesuspendeerde deeltjes zullen voorkomen tijdens de boorfase, door periodieke (bulk) lozingen die plaatsvinden nadat een sectie is gecompleteerd. Er is bijvoorbeeld ingeschat dat tijdens het boren van een productieput voor de ontwikkeling van een gasveld, de drempelwaarde van $200 \mathrm{mg} / \mathrm{l}$ (waarboven effecten kunnen worden verwacht; Jak et al., 2000) kan worden overschreden binnen een maximale afstand tot het lozingspunt van 30 - 40 m. Deze concentraties zouden maximaal gedurende 1 à 2 uur per geval optreden (Tamis et al., 2011). Tweekleppigen zijn, vanwege hun aanpassingsmechanismen, in het algemeen vrij tolerant voor vertroebeling. Dit betekent echter niet dat ze geen effect ondervinden door blootstelling aan vertroebeling. Effecten zijn onder andere vermindering van voedselactiviteit en respiratie en verhoging van de pseudofaecesproductie en energieverbruik (Wilber \& Clarke 2001). Langdurig verhoogde blootstelling (> 5 dagen boven de drempelwaarde van $200 \mathrm{mg} / \mathrm{l}$ ) kan reductie in groei en reproductie veroorzaken en uiteindelijk verhoogde mortaliteit (Jak et al., 2000; Wilber \& Clarke 2001). Een randvoorwaarde voor het oesterrif is een laag ( $<90 \mathrm{mg} / \mathrm{l})$ zwevend stofgehalte (Smaal et al., 2017; Kamermans et al., 2018). Kortdurende vertroebeling en verhoging van sedimentatie zal naar verwachting geen groot effect hebben op een platteoesterrif en bijbehorende biota (Perry \& Tyler-Walters, 2016). Negatieve effecten door compensatie voor verhoogde zwevend stof concentraties zijn echter niet uit te sluiten. Op welke afstand tot het boorplatform een verhoogd zwevend stofgehalte (>90 mg/l) kan optreden en hoe lang dat duurt is op basis van deze quickscan niet in te schatten.

\subsubsection{Verstoring door geluid}

Volgens Europese regelgeving (EU, 2008) wordt onderscheid gemaakt tussen continu geluid en impulsgeluid. Continu geluid wordt (tijdelijk) veroorzaakt door transport (schepen en helikopters), tijdens het boren naar gas en bij normale bedrijfsvoering op productieplatforms. Impulsgeluid wordt veroorzaakt bij seismisch onderzoek en soms bij heiwerkzaamheden tijdens de boorfase (voordat met het boren wordt begonnen, wordt op de plaats van de put een zware metalen buis met een grote diameter enkele tientallen meters de grond in geheid of geboord). Aangezien veel mariene diersoorten geluid/trillingen gebruiken voor communicatie met soortgenoten en voor foerageren, kan geluid een belangrijke storingsfactor zijn voor fauna. Naast fysieke schade, kan geluidsbelasting ook leiden tot stress, verstoring van communicatie en/of gedragsverandering van individuen. Dit kan vervolgens weer leiden tot het verlaten van het leefgebied of bijvoorbeeld een afname van reproductie. In bepaalde gevallen kan ook gewenning optreden, in het bijzonder bij continu geluid.

Observaties in het veld tijdens seismisch onderzoek met grote airguns (79 en 110 liter) in British Columbia leverden vermijding van bruinvissen op tot $70 \mathrm{~km}$ afstand (Bain \& Williams, 2006). Ook werd in dezelfde studie vermijding door de gewone zeehond waargenomen. Omdat het geluidsniveau van de ontvanger afhangt van lokale factoren zoals diepte, sediment type en weersomstandigheden, zijn afstanden tot waar gehoorschade van zeezoogdieren door seismische activiteiten kan optreden 
lastig vast te stellen. Wel zijn geluidsniveaus van airguns bekend (Sound Pressure Level 160-261 dB re $1 \mu \mathrm{Pa}$ op $1 \mathrm{~m}$ afstand, afhankelijk van het type en formaat van de airgun: Ainslie et al., 2009; Kater et al., 2011), welke vergelijkbaar zijn met die van heien (Sound Pressure Level 210 - 257 (0-piek) dB re $1 \mu \mathrm{Pa}$ op $1 \mathrm{~m}$ afstand, afhankelijk van de diameter van de heipaal: Genesis Oil and Gas Consultants, 2011). De afstand tot waar permanente gehoorschade (PTS: permanent threshold shift) bij bruinvissen kan optreden ten gevolge van heien voor de installatie van offshore windturbines, is afhankelijk van de weerscondities, 0,5 tot 1,5 km (Heinis et al., 2015). In Nederland is binnen het kader Ecologie en Cumulatie (Heinis et al., 2015) een drempelwaarde (geluiddosis door een zwemmende dier ontvangen als gevolg van het heien van de gehele paal) van $164 \mathrm{~dB}$ re $\mu \mathrm{Pa}^{2} \mathrm{~s}$ voor tijdelijke gehoorschade (TTS: temporary threshold shift) en $179 \mathrm{~dB}$ re $\mu \mathrm{Pa}^{2} \mathrm{~s}$ voor permanente gehoorschade (PTS) gehanteerd.

Mitigerende maatregelen (zoals 'soft start' en 'acoustic deterrent device') kunnen mogelijk dergelijke effecten voorkomen (Heinis et al., 2015). Op basis van de geluidsemissie karakteristieken is de kans aanwezig dat ook seismische surveys kunnen leiden tot primaire beschadiging bij bruinvissen (De Haan et al., 2015). Indien zeezoogdieren dicht bij de geluidsbron aanwezig zijn, zal gehoorschade zeker optreden (UNEP/CBD, 2012). Naar verwachting zullen bruinvissen het platform tijdens heien tot op tientallen kilometers afstand vermijden (Dähne et al. 2013; Kastelein et al., 2013).

Ook vissen en ongewervelden kunnen gevoelig zijn voor onderwatergeluid (UNEP/CBD, 2012; Carroll et al., 2017). Fysieke schade van impulsief onderwatergeluid (zoals gehoorschade en gescheurde zwemblaas) is bekend bij vissen (UNEP/CBD, 2012). (Sub)-lethale effecten van onderwatergeluid zijn ook aangetoond voor kreeft (Day et al., 2016), inktvis (André et al., 2011) en tweekleppigen (Charifi et al., 2017; 2018; Day et al., 2016; 2017). Effecten van onderwatergeluid op de platte oester (Ostrea edulis) zijn onbekend. Wel blijkt op basis van (veld)onderzoek met andere soorten (Pecten fumatus, een mantelschelp) dat effect van seismisch onderzoek op schelpdierpopulaties significant verhoogde mortaliteit tot gevolg kan hebben (Day et al., 2016; 2017).

Japanse oesters (Magallana gigas) kunnen geluid waarnemen van onder andere scheepvaart, seismisch onderzoek, heien, boren en wind turbines (Charifi et al., 2017). Bij langdurige blootstelling van Japanse oesters aan scheepvaartgeluid (14 dagen) was een verminderde activiteit (o.a. filtratie, klepbeweging) en groei waargenomen (Charifi et al., 2018). Er is bij de mantelschelp Pecten fumatus geen directe massale sterfte waargenomen maar wel een verhoogde mortaliteit in de periode na blootstelling aan het geluid. Ook zijn er fysiologische effecten (langdurige verandering bloedwaarden) en gedragseffecten waargenomen (Day et al., 2016; 2017). De organismen waren blootgesteld aan geluid vergelijkbaar met airguns die op een afstand variërend van 114 tot 875 meter passeren (Day et al., 2016). Schelpdierlarven (Pecten novaezelandiae, een mantelschelp) vertoonden een verstoorde ontwikkeling na blootstelling aan onderwatergeluid (de Soto et al., 2013). Bij kortdurende blootstelling (enkele uren) van de gewone mossel Mytilus edulis aan onderwatergeluid door heien is een verhoogde voedselactiviteit waargenomen, wat mogelijk een stressreactie kan zijn (Spiga et al., 2016).

Op basis van de hierboven beschreven informatie lijkt het mogelijk dat (significant verhoogde) mortaliteit, fysiologische effecten en gedragseffecten kunnen optreden bij platte oesters en andere tweekleppigen als gevolg van blootstelling aan onderwatergeluid door het gebruik van seismische airguns.

\subsubsection{Verstoring door licht en optische verstoring}

Door de emissie van licht kunnen vogels en zeezoogdieren verstoord worden. Sommige vogelsoorten vermijden platforms en veranderen vaak van richting om op een grotere afstand te passeren. Anderen worden aangetrokken door platformverlichting. Het effect van verlichting op zee op bepaalde trekvogels is aanzienlijk (Marquenie \& van der Laar, 2004). Dit zijn voornamelijk zangvogels. Ook andere vogelsoorten, zoals de Kleine mantelmeeuw, de Grote mantelmeeuw en de Zeekoet, zijn echter's nachts waargenomen bij een platform dat ca. $20 \mathrm{~km}$ ten noorden van Texel buiten de Noordzeekustzone ligt (van der Laar, 2007). Het risico op effecten van licht van offshore installaties (verstoring vliegpatroon van vogels) kan gereduceerd worden door de horizontale en verticale lichtdispersie af te schermen. 
Optische verstoring is verstoring door de aanwezigheid en/of beweging van mensen dan wel voorwerpen die niet thuishoren in het natuurlijke systeem. Doorgaans zal er sprake zijn van een cumulatie van visuele verstoring en storing door geluid, licht en/of trilling, aangezien de aanwezigheid van een object vaak gepaard gaat met dergelijke storingsfactoren. Sommige zeevogels (voornamelijk meeuwen) gebruiken platforms om te rusten, andere vogelsoorten houden grote afstand (1000 meter) tot vaste offshore constructies, zoals de Grote stern en de Zwarte zee-eend (Jak et al., 2000; Marquenie \& van der Laar, 2004). Ook de helikopters en bevoorradingsschepen kunnen optische verstoring veroorzaken. Onder water speelt dit probleem waarschijnlijk niet, maar hier is verder geen onderzoek naar gedaan.

\subsection{Overige risico's}

Naast de potentiële effecten ten gevolge van de drukfactoren die door olie- en gasactiviteiten worden veroorzaakt zijn er nog risico's voor de natuur door incidenten/calamiteiten, zoals een aanvaring tussen een schip en een platform. Kansen op deze gebeurtenissen zijn onder meer afhankelijk van de nabijheid van scheepvaartroutes terwijl de gevolgen sterk afhangen van de omstandigheden zoals snelheid van de aanvaring, grootte van het schip (NOGEPA, 2001). Eventuele gevolgen voor het milieu kunnen daarom variëren van nihil tot zeer ernstig, zoals een blow-out. Een blow-out is een ongecontroleerde uitstroming uit een put, waarbij koolwaterstoffen (olie en/of gas), boorspoeling of water vrijkomen (NOGEPA, 2001). Blow-outs kunnen ook optreden bij het boren naar nieuwe olie- of gasvoorkomens of bij ontwikkelingsboringen, maar ook tijdens productie, door bijvoorbeeld lekkages, aanvaringen, brand of explosie op het platform of tijdens onderhoudswerkzaamheden aan de put. Een platform is uitgerust met een speciale blow-out preventer, die de bron kan afsluiten zodra zich een gevaarlijke situatie voordoet. In geval van een blow-out van een gasput zal zowel gas als condensaat vrijkomen. Het gas zal zich snel in de lucht verspreiden. Lokale effecten op het mariene milieu zullen vooral door het vrijgekomen condensaat worden veroorzaakt, wat zich in zee zal verspreiden in een dunne film op het wateroppervlak. De halfwaardetijd voor het verdwijnen van een vlek (door de zwaartekracht, wind, zeecondities, verdamping en dispersie) bedraagt voor condensaat ca. 4 uur (NOGEPA, 2001).

Incidentele milieubelasting kan tevens optreden door spills. Onder spills worden verstaan lozingen die niet samenhangen met de normale bedrijfsvoering, maar het gevolg zijn van onvoorziene zaken, zoals door overslagincidenten, opslagincidenten, procesincidenten of pijpleidingincidenten. Spills van milieubelastende vloeistoffen zijn bijvoorbeeld olie, condensaat, diesel, mijnbouwhulpstoffen, boorspoelingchemicaliën. Eventuele effecten op de aanwezige natuurwaarden zijn afhankelijk van de aard en de omvang van de spill en de lokale milieucondities.

Mogelijke bodemdaling en aardbevingen in het gebied als gevolg van de activiteiten zijn niet onderzocht. Ook mogelijke effecten daarvan op de natuurwaarden in het gebied zijn niet onderzocht. Naar verwachting zal bodemdaling gezien de waterdiepte in het gebied verwaarloosbare effecten hebben. Het lijkt aannemelijk dat aardbevingen mogelijk het kwetsbare rifhabitat kunnen verstoren.

\subsection{Potentiële effecten op benthos en platte oesters in het bijzonder}

Alle hierboven genoemde drukfactoren als gevolg van offshore activiteiten ten behoeve van gaswinning, met uitzondering van optische verstoring / verstoring door licht, kunnen potentieel effect hebben op bodemdieren (benthos). Voor de goede/succesvolle ontwikkeling van het oesterrif dat recentelijk is aangelegd zijn er belangrijke randvoorwaarden: een lage bodemdynamiek; een laag zwevend stofgehalte ( $<90 \mathrm{mg} / \mathrm{l})$; temperatuur tussen de 3 en $30^{\circ} \mathrm{C}$; de sedimentsamenstelling (stevig slibbig zand, slibbig gravel met schelpen, stenen is optimaal; zand met korrelgrootte tussen 63 en 210 $\mu \mathrm{m}$ is geschikt); voldoende voedselaanbod; zuurstofgehalte (>0,5 mg/l); waterdiepte (1-80 m diep); saliniteit (20-35 \%o); stroomsnelheid $(<0,8 \mathrm{~m} / \mathrm{s})$; minimale predatie en competitie; en de mogelijkheid 
voor succesvolle rekrutering, wat afhangt van de omvang van de ouderpopulatie en de aanvoer van larven door middel van de waterbeweging (Smaal et al., 2017; Kamermans et al., 2018). Offshore activiteiten ten behoeve van gaswinning kunnen mogelijk invloed hebben op deze factoren:

booractiviteiten (lozing van boorspoeling en boorgruis) kunnen potentiële effecten veroorzaken op de bodemdynamiek, de sedimentsamenstelling en het zwevend stofgehalte. Daarnaast zijn er (potentieel dodelijke) effecten van onderwatergeluid door seismisch onderzoek en booractiviteiten mogelijk. Mogelijke mitigerende maatregelen, zoals het afvoeren van boorspoeling en -gruis, her-injectie van productiewater en geluid reducerende maatregelen tijdens het boren, zouden zorgvuldig moeten worden afgewogen. Het is op basis van dit beknopte onderzoek en de hierin onderzochte literatuur niet mogelijk een uitspraak te doen op welke afstand er geen effecten door offshore activiteiten ten behoeve van gaswinning op het oesterrif kunnen optreden.

\subsection{Cumulatieve impacts}

De cumulatieve effecten van menselijk handelen is een belangrijke aandachtspunt van het Noordzee beheer en beleid (Ministerie van IenW \& LNV, 2018). Het meenemen van cumulatie in plannen en projecten is sinds januari 2017 in de Nederlandse wetgeving geïmplementeerd in artikel 7.23, lid 1 sub f van de Wet milieubeheer. Ook heeft het Rijk zichzelf gebonden aan het opstellen en toepassen van een Kader Ecologie en Cumulatie voor de ontwikkeling van windenergie op zee (Rijkswaterstaat, 2019). Daarbij spelen cumulatieve effecten van onderwatergeluid door heien op bruinvissen een belangrijke rol (Heinis et al., 2015; 2019).

Met betrekking tot het oesterrif zijn cumulatieve effecten zeker ook van belang. Het wordt mogelijk geacht dat er door blootstelling aan geluid van seismisch onderzoek in combinatie met andere stressoren mortaliteit kan optreden bij schelpdieren (Day et al., 2016; 2017; Przeslawski et al., 2018). 


\section{$4 \quad$ Kwaliteitsborging}

Wageningen Marine Research beschikt over een ISO 9001:2015 gecertificeerd kwaliteitsmanagementsysteem. Dit certificaat is geldig tot 15 december 2021. De organisatie is gecertificeerd sinds 27 februari 2001. De certificering is uitgevoerd door DNV GL. 


\section{Literatuur}

Ainslie M.A., C.A.F. de Jong, H.S. Dol, G. Blacquière, C. Marasini (2009). Assessment of natural and anthropogenic sound sources and acoustic propagation in the North Sea. TNO-DV 2009 C085

André, M., Solé, M., Lenoir, M., Durfort, M., Quero, C., Mas, A., Lombarte, A., Van Der Schaar, M., López-Bejar, M., Morell, M., Zaugg, S., Houégnigan, L. (2011). Low-frequency sounds induce acoustic trauma in cephalopods. Frontiers in Ecology and the Environment, 9 (9), pp. 489-493. DOI: $10.1890 / 100124$

Bain, D. E. \& Williams, R. ( 2006).: Long-range effects of airgun noise on marine mammals: responses as a function of received sound level and distance. Paper SC/58/E35. IWC Scientific Committee, June 2006, St Kitts and Nevis.

Bos O.G., S. Glorius, J.W.P. Coolen, J. Cuperus, B. van der Weide, A. Aguera Garcia, P.W. van Leeuwen, W. Lengkeek, S. Bouma, M. Hoppe, H. van Pelt (2014). Natuurwaarden Borkumse Stenen. Project Aanvullende beschermde gebieden. Wageningen IMARES Rapport C115.14

Carroll, A. G., Przeslawski, R., Duncan, A., Gunning, M., \& Bruce, B. (2017). A critical review of the potential impacts of marine seismic surveys on fish $\&$ invertebrates. Marine pollution bulletin, 114(1), 9-24.

Charifi M, Miserazzi A, Sow M, Perrigault M, Gonzalez P, Ciret P, et al. (2018). Noise pollution limits metal bioaccumulation and growth rate in a filter feeder, the Pacific oyster Magallana gigas. PLoS ONE 13(4): e0194174. https://doi.org/10.1371/journal.pone.0194174

Charifi, M., Sow, M., Ciret, P., Benomar, S., Massabuau, J.-C. (2017). The sense of hearing in the Pacific oyster, Magallana gigas. PLoS ONE, 12 (10), art. no. e0185353. DOI: 10.1371/journal.pone.0185353

Coolen, J. W. P. (2017). North Sea Reefs. Benthic biodiversity of artificial and rocky reefs in the southern North Sea. Thesis. Wageningen University \& Research. https://library.wur.nl/WebQuery/wurpubs/515656

Coolen, J. W. P., et al. 2015. Reefs, sand and reef-like sand: A comparison of the benthic biodiversity of habitats in the Dutch Borkum Reef Grounds. Journal of Sea Research: 1 - 9.

Dähne M., A. Gilles, K. Lucke, V. Peschko, S. Adler, K. Krügel, J. Sundermeyer \& U. Siebert (2013).: Effects of pile-driving on harbour porpoises (Phocoena phocoena) at the first offshore wind farm in Germany. Environ. Res. Lett. 8 (2012) 025002, 16p. doi:10.1088/1748-9326/8/2/025002.

Day, R. D., McCauley, R. D., Fitzgibbon, Q. P., Hartmann, K., \& Semmens, J. M. (2017). Exposure to seismic air gun signals causes physiological harm and alters behavior in the scallop Pecten fumatus. Proceedings of the National Academy of Sciences, 114(40), E8537-E8546..

Day, R. D., McCauley, R. D., Fitzgibbon, Q. P., Hartmann, K., \& Semmens, J. M. (2016). Assessing the impact of marine seismic surveys on Southeast Australian scallop and lobster fisheries. University of Tasmania, Hobart. FRDC Report 2012/008.

De Haan, D., S. Benda von Beckmann, S. Geelhoed \& S. Lagerveld (2015).: Potential effects of seismic surveys on harbour porpoises. IMARES report C126/15.

De Soto, N. A., Delorme, N., Atkins, J., Howard, S., Williams, J., \& Johnson, M. (2013). Anthropogenic noise causes body malformations and delays development in marine larvae. Scientific reports, 3, 2831.

Didderen et al., (in prep.). Experiment to actively restore native oysterbank in the North Sea: Installation of Borkum Reefground pilot and first monitoring 2018. Final Draft version.

Duineveld GCA, Bergman MJN, Lavaleye MSS (2007) Effects of an area closed to fisheries on the composition of the benthic fauna in the southern North Sea. ICES J Mar Sci 64:899-908

Duren A. van, A. Gittenberger, A.C. Smaal, M. van Koningsveld, R. Osinga, J.A. Cado van der Lelij \& M.B. de Vries, 2016. Rijke riffen in de Noordzee Verkenning naar het stimuleren van natuurlijke riffen en gebruik van kunstmatig hard substraat. Deltares 2016.

Europese Unie (2008). Richtlijn 2008/56/EG van het Europees Parlement en de Raad van 17 juni 2008 tot vaststelling van een kader voor communautaire maatregelen betreffende het beleid ten aanzien van het mariene milieu (Kaderrichtlijn mariene strategie).

http://data.europa.eu/eli/dir/2008/56/oj 
Genesis Oil and Gas Consultants (2011). Review and Assessment of Underwater Sound Produced from Oil and Gas Sound Activities and Potential Reporting Requirements under the Marine Strategy Framework Directive. 2011. Genesis Oil and Gas Consultants report for the Department of Energy and Climate Change.

Heinis F., C.A.F. de Jong, S. von Benda-Beckmann \& B. Binnerts (2019). Kader Ecologie en Cumulatie - 2018. Cumulatieve effecten van aanleg van windparken op zee op bruinvissen. TNO \& HWE rapport 18.153RWS_KEC2018

Heinis F., C.J. de Jong \& Werkgroep Onderwatergeluid (2015). Cumulatieve effecten van impulsief onderwatergeluid op zeezoogdieren. TNO rapport TNO 2015 R10335.

Herman P., Beauchard O., \& van Duren L., 2014. De Staat van de Noordzee. Noordzeedagen 2015. http://www.noordzeedagen.nl/nl/noordzeedagen/Vorige-edities/Noordzeedagen-2014-1/ThemaLeven-met-een-veranderende-Noordzee-Horizon-2050./De-staat-van-de-Noordzee.htm

Jak RG, Kaag NHBM, Schobben HPM, Scholten MCT, Karman CC, Schobben JHM (2000) Kwantitatieve verstoring-effect relaties voor AMOEBE soorten, TNO-MEP rapport.

Joschko, T.J., Buck, B.H., Gutow, L., Schröder, A., 2008. Colonization of an artificial hard substrate by Mytilus edulis in the German Bight. Mar. Biol. Res. 4, 350-360. http:// dx.doi.org/10.1080/17451000801947043.

Kamermans P., B. Walles, M. Kraan, L.A. van Duren, F. Kleissen \& T.M. van der Have, A.C. Smaal, M. Poelman (2018) Offshore wind farms as potential locations for flat oyster (Ostrea edulis) restoration in the 1 Dutch North Sea. Sustainability 10, 3942; doi:10.3390/su10113942

Kastelein, R.A., D. van Heerden, R. Gransier \& L. Hoek (2013): Behavioral responses of a harbor porpoise (Phocoena phocoena) to playbacks of broadband pile driving sounds. Marine Environmental Research 92: 206-214.

Kater B., G. Lipari, R. Snoek, D. van Hogendorp, M. Jaarsma, F. van Heemskerck Pillis \& S. van der Zon (2011): Seismisch onderwatergeluid op het Nederlands Continentaal Plat. ARCADIS Nederland BV in opdracht voor Rijkswaterstaat Dienst Noordzee, April 2011. C04021.002690.

Lengkeek W., K. Didderen, M. Teunis, F. Driessen, J.W.P Coolen, O.G. Bos, S.A.Vergouwen, T.C. Raaijmakers, M.B.de Vries, M. van Koningsveld (2017) Eco-friendly design of scour protection: potential enhancement of ecological functioning in offshore wind farms. Towards an implementation guide and experimental set-up. Bureau Waardenburg report nr 17-001

Marquenie J.M. \& F.J.T. van der Laar (2004): Protecting migrating birds from offshore production. EP 2003-7308.

Millican P.F. \& M.M. Helm, 1994. Effects of nutrition on larvae production in the European flat oyster, Ostrea edulis. Aquaculture 123: 83-94

Ministerie van Infrastructuur en Waterstaat \& Ministerie van Landbouw, Natuur en Voedselkwaliteit (2018): Mariene Strategie (deel 1). Actualisatie van huidige milieutoestand, goede milieutoestand, milieudoelen en indicatoren. 2018-2024. Juni 2018. Te downloaden via: https://www.rijksoverheid.nl/regering/bewindspersonen/cora-vannieuwenhuizen/documenten/rapporten/2018/06/21/bijlage-5-mariene-strategie

NOGEPA (2001). Generiek document m.e.r. offshore. Basisdocument voor de milieu-effectrapportage bij olie- en gaswinning op het Nederlands Continentaal Plat.

Perry, F. \& Tyler-Walters, H., 2016. [Ostrea edulis] beds on shallow sublittoral muddy mixed sediment. In Tyler-Walters H. and Hiscock K. (eds) Marine Life Information Network: Biology and Sensitivity Key Information Reviews, [on-line]. Plymouth: Marine Biological Association of the United Kingdom. [cited 29-01-2019]. Available from: https://www.marlin.ac.uk/habitat/detail/69

Przeslawski, R., Huang, Z., Anderson, J., Carroll, A. G., Edmunds, M., Hurt, L., \& Williams, S. (2018). Multiple field-based methods to assess the potential impacts of seismic surveys on scallops. Marine pollution bulletin, 129(2), 750-761.

Rijkswaterstaat (2019). Kader Ecologie en Cumulatie 3.0: Beschrijving en beoordeling van cumulatieve effecten bij uitvoering van de routekaart windenergie op zee tot 2030. Deelrapport C: Samenvatting. Beschikbaar via: https://www.noordzeeloket.nl/functies-gebruik/windenergiezee/ecologie/wind-zee-ecologisch/documenten-wozep-0/kader-ecologie/

Sas H., P. Kamermans, T. van der Have, W. Lengkeek \& A. Smaal, 2016. Shellfish reef restoration pilots, Voordelta, The Netherlands. Annual report 2016.

Smaal A., P. Kamermans, F. Kleissen, L. van Duren \& T. van der Have, 2016. Platte oesters in offshorewindparken (POP). Wageningen, Wageningen Marine Research rapport C035/17. $52 \mathrm{blz}$. http://edepot.wur.nl/412950 
Smaal A., P. Kamermans, F. Kleissen, L. van Duren \& T. van der Have. 2017. Flat oysters on offshore wind farms. Wageningen, Wageningen Marine Research rapport C052/17. https://doi.org/10.18174/418092

Smaal, A.C., P. Kamermans, van der Have, M. Engelsma \& H.J.W. Sas, 2015. Feasibility of Flat Oyster (Ostrea edulis L.) restoration in the Dutch part of the North Sea, IMARES reportC028/15.

Spiga, I., Caldwell, G.S., Bruintjes, R. (2016). Influence of pile driving on the clearance rate of the blue mussel, Mytilus edulis (L.) Proceedings of Meetings on Acoustics, 27 (1), art. no. 040004. DOI: $10.1121 / 2.0000277$

Tamis, J.E.; Karman, C.C.; Vries, P. de; Jak, R.G.; Klok, T.C. (2011). Offshore olie- en gasactiviteiten en Natura 2000: inventarisatie van mogelijke gevolgen voor de instandhoudingsdoelen van de Noordzee. Den Helder : IMARES (Rapport / Imares Wageningen UR C144/10).

UNEP/CBD (2012): Scientific synthesis on the impacts of underwater noise on marine and coastal biodiversity and habitats. UNEP/CBD/SBSTTA/16/INF/12, 12 March 2012

Van der Laar (2007) Green light to birds: Investigation into the effect of bird-friendly lighting.

Vrooman, J., van Sluis, C., van Hest, F., 2018. Gebiedsbescherming op de Nederlandse Noordzee. De stand van zaken in relatie tot visserij. Stichting De Noordzee, Utrecht.

Widdows, J., Fieth, P. \& Worrall, C.M., 1979. Relationships between seston, available food and feeding activity in the common mussel Mytilus edulis. Marine Biology, 50(3), pp.195-207.

Wilber, D.H. \& Clarke, D.G., 2001. Biological Effects of Suspended Sediments: A Review of Suspended Sediment Impacts on Fish and Shellfish with Relation to Dredging Activities in Estuaries. North American Journal of Fisheries Management, 21(December 2016), pp.855-875.

Yildiz, Harun, Berber, Selcuk, \& Acarli, Sefa, 2011. Seasonal variation in the condition index, meat yield and biochemical composition of the flat oyster Ostrea edulis (Linnaeus, 1758) from the Dardanelles, Turkey. Italian journal of animal science Volume: 10 Issue: 1 Pages: 22-26 


\section{Verantwoording}

Rapport C033/20

Projectnummer: 4312100100

Dit rapport is met grote zorgvuldigheid tot stand gekomen. De wetenschappelijke kwaliteit is intern getoetst door een collega-onderzoeker en het verantwoordelijk lid van het managementteam van Wageningen Marine Research

Akkoord:

Oscar Bos

Handtekening:
Datum:

Akkoord:

Jakob Asjes

Manager Integratie

Handtekening:

Datum:

22 februari 2019 
Wageningen Marine Research

T: $+31(0) 317480900$

E: marine-research@wur.nl

www.wur.nl/marine-research

Bezoekers adres:

- Ankerpark 271781 AG Den Helder

- Korringaweg 7, 4401 NT Yerseke

- Haringkade 1, 1976 CP IJmuiden
Wageningen Marine Research levert met kennis, onafhankelijk wetenschappelijk onderzoek en advies een wezenlijke bijdrage aan een duurzamer, zorgvuldiger beheer, gebruik en bescherming van de natuurlijke rijkdommen in zee-, kust- en zoetwatergebieden.
Wageningen Marine Research is onderdeel van Wageningen University \& Research. Wageningen University \& Research is het samenwerkingsverband tussen Wageningen University en Stichting Wageningen Research en heeft als missie: 'To explore the potential of nature to improve the quality of life' 